\title{
Effect of transoral endoscopic adenoidectomy on peripheral blood T-lymphocyte subsets in children with obstructive sleep apnea-hypopnea syndrome and its treatment strategy
}

\author{
NA YANG, YAOFENG JI and YIN LIU \\ Department of Otolaryngology, Xuzhou Children's Hospital, Xuzhou, Jiangsu 221002, P.R. China
}

Received October 19, 2016; Accepted April 7, 2017

DOI: $10.3892 /$ etm.2017.4851

\begin{abstract}
The objective of the present study was to investigate the effect of transoral endoscopic adenoidectomy on peripheral blood $\mathrm{T}$ lymphocyte subsets in pediatric patients with obstructive sleep apnea-hypopnea syndrome (OSAHS) and its treatment strategy. Ninety-eight pediatric patients with adenoidal hypertrophy associated with OSAHS admitted to the Department of Otolaryngology, Xuzhou Children's Hospital were selected. After admission, patients received perfected $24 \mathrm{~h}$ polysomnogram monitoring, routine blood examination, fasting blood biochemistry examination, T-lymphocyte subset count, $24 \mathrm{~h}$ ambulatory blood pressure monitoring, and nasopharyngeal computed tomography. After patients were diagnosed with adenoidal hypertrophy associated with OSAHS, they underwent transoral endoscopic adenoidectomy with a power microdebrider. Patients were evaluated at 3-, 6- and 12-week follow-up visits. The $\mathrm{CD}^{+}$, $\mathrm{CD}^{+}$, and $\mathrm{CD}^{+} \mathrm{T}$-cell counts, $\mathrm{CD} 4^{+} / \mathrm{CD}^{+} \mathrm{T}$ lymphocyte ratio, and changes of $24 \mathrm{~h}$ ambulatory blood pressure before and after surgery were recorded. After the 6-week follow-up visit, the mean $\mathrm{CD}^{+} \mathrm{T}$ lymphocyte count in patients was increased significantly compared with that before surgery, the $\mathrm{CD}^{+} / \mathrm{CD}^{+} \mathrm{T}$ lymphocyte ratio increased gradually, and the differences were statistically significant $(\mathrm{P}<0.05)$. The frequency of nocturnal awakening of patients was decreased significantly after surgery and the duration of nocturnal sleep was extended significantly $(\mathrm{P}<0.05)$. Through analysis of the preoperative and postoperative clinical data of pediatric patients, the $\mathrm{CD}^{+} / \mathrm{CD}^{+} \mathrm{T}$ lymphocyte ratio was negatively correlated with mean arterial pressure (MAP) $(r=-1.06$, $\mathrm{P}=0.003$ ). In conclusion, adenoidectomy can significantly decrease the MAP in pediatric patients with OSAHS and increase the duration of nocturnal sleep. The peripheral blood
\end{abstract}

Correspondence to: Dr Yin Liu, Department of Otolaryngology, Xuzhou Children's Hospital, 18 Sudibei Road, Xuzhou, Jiangsu 221002, P.R. China

E-mail: liuyin3636@sina.com

Key words: adenoidectomy, obstructive sleep apnea-hypopnea syndrome, T-cell subset, mean arterial pressure
$\mathrm{CD}^{+} / \mathrm{CD}^{+} \mathrm{T}$ lymphocyte ratio in pediatric patients was significantly negatively correlated with MAP.

\section{Introduction}

Obstructive sleep apnea-hypopnea syndrome (OSAHS) is the clinical syndrome characterized by relapses of apnea and/or hypopnea, hypercapnia, and sleep interruption caused by a variety of factors that lead to pathophysiologic changes in the body (1). OSAHS is a very common otorhinolaryngological disease in children that can cause a series of complicated pathophysiologic processes in the body, leading to different degrees of recurrent airway dysfunction (2). The clinical significance of OSAHS is not simply limited to influencing the normal sleep of pediatric patients. At present, studies have shown that OSAHS is closely related to many serious diseases, such as cardiovascular, nerve and metabolic disease $(3,4)$. According to Feng et al, OSAHS can cause fluctuations of thyroid hormone levels in children, the inability to concentrate, and lower the quality of life (5). In addition, Sforza et al, reported that the mean body mass index (BMI) of most children with OSAHS was significantly higher than that of normal children (6). Furthermore, acute changes of oxyhemoglobin saturation in children with OSAHS during the process of nocturnal sleep can cause hypoxia stress (7), resulting in the release of inflammatory cells and inflammatory cytokines, such as lymphocytes, neutrophils, TREM-1, and pentraxin-3. These inflammatory cells and cytokines can cause endothelial injury and further aggravate obesity (8) and hypertension (9). Obesity is the most dangerous pathogenic factor causing OSAHS (10). The brain is the organ with the largest oxygen consumption in the body during sleep. Therefore, Roubille et al (11) hypothesized that hypoxia during sleep can lead to local cerebral blood flow obstruction. After the diagnosis of OSAHS, positive and effective treatment measures should be taken to prevent a series of pathological reactions caused by OSAHS. The therapeutic regimen of OSAHS should be determined primarily according to the pathogenesis and clinical manifestations of pediatric patients.

In China, there is a lack of understanding of OSAHS in children. Therefore, according to recent guidelines on pediatric OSAHS from the American Academy of Pediatrics (1), polysomnogram (PSG) monitoring should be performed for patients with obvious signs and symptoms, to monitor the nocturnal 
sleep disorder process and help provide corresponding treatment. However, it is insufficient for the therapeutic regimen to depend only on the results of PSG combined with clinical manifestations. The systematic evaluation of risk factors of OSAHS in children is necessary to achieve individualized treatment (12).

Increasing evidence has indicated that OSAHS can be treated with drugs, such as steroids or montelukast. However, this is only limited to pediatric patients with apnea-hypopnea index (AHI) grading between 5 and 20. For patients with AHI grading $>20$, adenoidectomy can serve as a form of clinical treatment for effectively controlling OSAHS. Some pediatric patients with OSAHS are accompanied by adenoidal hypertrophy. These patients are usually treated with adenoidectomy or transoral endoscopic adenoidectomy (13). In the present study, transoral endoscopic adenoidectomy was performed and changes of preoperative and postoperative peripheral blood T lymphocyte subsets in children with OSAHS were analyzed, to investigate the influence of OSAHS on the immune system.

\section{Patients and methods}

Patients. After obtaining approval from the Xuzhou Children's Hospital Ethics Committee and informed consent from the family of patients, 98 pediatric patients with OSAHS diagnosed via auxiliary diagnostic methods, such as with an imaging and sleep breathing detector, were screened, including 49 males and 49 females, with an average age of $4.61 \pm 1.57$ years. The disease duration was $1.5-4.5$ years, with an average of $2.32 \pm 1.27$ years. After admission, the patients received perfected clinical routine blood examination, blood biochemistry examination, $24 \mathrm{~h}$ sleep breathing detection, and $24 \mathrm{~h}$ ambulatory blood pressure monitoring. The general clinical conditions of pediatric patients are shown in Table I.

Inclusion and exclusion criteria. Inclusion criteria for the study were: i) Patients who were diagnosed with adenoidal hypertrophy associated with OSAHS via clinical examination, medical history, and clinical manifestations; ii) patients who cried loudly during the process of examination and treatment, and whose families agreed to the use of sedative drugs; iii) patients whose adenoid was the only cause of OSAHS; and iv) patients without history of palatorrhaphy.

Exclusion criteria for the study were: i) Patients with lung diseases such as bronchial asthma, lung tissue cystic fibrosis, and active tuberculosis; ii) patients with malignant tumors in the respiratory system; iii) patients who underwent surgery, suffered trauma in a traffic accident, or had infections in other parts of the body; iv) patients with central sleep apnea syndrome, thyroid hypofunction, acromegaly, narcolepsy, laryngospasm, vocal cord paralysis, epilepsy, or neuromuscular disease; v) patients with cognitive impairment or mental disease; vi) patients whose blood sample failed to be obtained; vii) patients with dysfunction of bleeding or blood coagulation; viii) patients with suspected middle ear effusion according to acoustic immitance test; ix) patients with submucous cleft palate; $x$ ) patients lost to follow-up; and $\mathrm{xi}$ ) patients or their families who failed to cooperate in examination and treatment.
Examination methods. Routine blood and blood biochemical examination: Sterile whole venous blood (4-6 ml) was drawn and placed in BD vacuum sterile sodium citrate anticoagulation tubes. Monoclonal antibody measurements (Bio-Rad Laboratories, Inc., Hercules, CA, USA) were used for the quantitative detection and analysis of T lymphocyte subsets; a fully-automated biochemical detector (Abbott Laboratories, Abbott Park, IL, USA) was used for blood biochemical examination.

Diagnostic criteria of nasopharyngeal true lateral X-ray: The vertical distance from the most projecting point of the adenoid to the surface of the skull base bone was taken as the thickness of the adenoid. The distance from the rear end of the hard palate to the intersection of the alar plate and skull base was taken as the width of the nasopharyngeal airway. The ratio between the thickness of the adenoid and the width of the nasopharyngeal airway was taken as the judgment standard:

i) Diagnostic range of the ratio between the thickness of the adenoid and the width of the nasopharyngeal airway (A/N value): Normal, A/N 0.5-0.6; severe hypertrophy, A/N 0.61-0.70; pathologic hypertrophy, A/N >0.71.

ii) Anteroposterior diameter (D-value) of effective nasopharyngeal cavity airway: Normal, $>4 \mathrm{~mm}$; adenoidal hypertrophy, $<3 \mathrm{~mm}$.

PSG. A PSG monitor (SOMNOmedics GmbH, Randersacker, Germany) was used to monitor indicators including the EEG and $24 \mathrm{~h}$ ambulatory blood pressure, snoring frequency and phase angle, respiratory gas plethysmography, carbon dioxide, oxyhemoglobin saturation, Cheyne-Stokes respiration, odontoprisis, body temperature, and EEG spike wave. The highest sample frequency was $2,048 \mathrm{~Hz}$.

i) AHI grading of OSAHS: Mild, AHI 5-20; moderate, AHI 21-40; severe, AHI >40.

ii) Hypoxemia grading of OSAHS: Mild, $\mathrm{SaO}_{2 \min }>85 \%$; moderate, $\mathrm{SaO}_{2 \min } 65-84 \%$; severe, $\mathrm{SaO}_{2 \min }<65$.

Note: OSAHS grading was based on AHI, and the condition of hypoxemia was indicated. For example, for $\mathrm{AHI}=25$ and minimum $\mathrm{SaO}_{2}(\%)=88$, it was reported as 'moderate OSHAS complicated with mild hypoxemia'.

Transoral endoscopic adenoidectomy (13). i) Preoperative evaluation: a) Before surgery, the general condition of patients was examined, and other potential diseases were ruled out; b) comprehensive physical examination and medical history was collected; and c) nasopharyngeal true lateral X-ray was performed.

ii) Construction of the oral channel: During tracheal intubation under general anesthesia, a Boyle-Davis mouth opener was used to keep the mouth open. The bilateral rubber hose was inserted from the nose end to the mouth end, and both ends were clamped with an artery clamp. The bilateral rubber hose was retracted, and the oral channel was constructed.

iii) Connection: A $70^{\circ}$, 4-mm Hopkins nasal endoscope was used through the constructed oral channel, and the quality of the adenoid was determined.

iv) Adenoidectomy: The cameras in the endoscope were installed, and the endoscope was connected to the monitor. After the imaging was clear, the special endoscope adenoid 
Table I. General clinical conditions of 98 pediatric patients with OSAHS (mean $\pm \mathrm{SD})$.

\begin{tabular}{lcccccc}
\hline Age (years) & $\begin{array}{c}\text { Duration of } \\
\text { OSAHS (months) }\end{array}$ & $\begin{array}{c}\text { Fasting blood } \\
\text { glucose (mmol/l) }\end{array}$ & $\begin{array}{c}\text { MAP } \\
(\mathrm{mmHg})\end{array}$ & $\begin{array}{c}\text { TG } \\
(\mathrm{mmol} / \mathrm{l})\end{array}$ & $\begin{array}{c}\text { LDL-C } \\
(\mathrm{mmol} / \mathrm{l})\end{array}$ & $\begin{array}{c}\text { BMI } \\
\left(\mathrm{kg} / \mathrm{m}^{2}\right)\end{array}$ \\
\hline $4.78 \pm 1.64$ & $2.38 \pm 1.67$ & $5.47 \pm 1.82$ & $108.2 \pm 12.1$ & $1.59 \pm 0.44$ & $3.10 \pm 1.49$ & $21.43 \pm 3.48$
\end{tabular}

\begin{tabular}{|c|c|c|c|c|c|}
\hline $\mathrm{A} / \mathrm{N}$ & D-value (mm) & $\begin{array}{l}\text { Duration of } \\
\text { continuous } \\
\text { sleep (min) }\end{array}$ & $\begin{array}{c}\text { Time of sleep } \\
\text { awakening }\end{array}$ & AHI & $\begin{array}{c}\text { Average } \\
\text { oxyhemoglobin } \\
\text { saturation } \\
\text { during sleep }\end{array}$ \\
\hline $0.79 \pm 0.22$ & $2.12 \pm 0.74$ & $384.33 \pm 24.78$ & $18.73 \pm 7.92$ & $48.33 \pm 12.78$ & $86.41 \pm 7.28$ \\
\hline
\end{tabular}

OSAHS, obstructive sleep apnea-hypopnea syndrome; MAP, mean arterial pressure; TG, triglyceride; LDL-C, low-density lipoprotein cholesterol; BMI, body mass index; AHI, apnea-hypopnea index.

Table II. Nasopharyngeal X-ray index evaluation for children with OSAHS before and after adenoidectomy (mean \pm SD).

\begin{tabular}{lccccr}
\hline Index & Case no. $(\mathrm{n})$ & Before surgery & After surgery & T-value & P-value \\
\hline A/N & 98 & $0.79 \pm 0.22$ & $0.23 \pm 0.15$ & 21.27 & 0.03 \\
D-value (mm) & 98 & $2.14 \pm 0.72$ & $4.42 \pm 1.68$ & 18.93 & 0.03 \\
\hline
\end{tabular}

OSAHS, obstructive sleep apnea-hypopnea syndrome.

curette was used to strike off most of the adenoid in the diseased region. St. Claire-Thomson forceps were used to remove residual adenoid tissues. Excessive intraoperative bleeding was usually rare, especially after nasopharyngeal lymphoid tissue was removed completely.

v) End of surgery: When surgery was close to completion, sterile gauze was inserted into the nasopharyngeal region of patients, and pressed for a few minutes until the tonsils were fully removed (patients complicated with tonsil hypertrophy could receive preventative tonsil removal). See the operative process.

Postoperative follow-up. We collected data on the clinical blood and biochemical indexes of patients after surgery by means of telephone, SMS, and WeChat follow-ups, and performed statistical analyses. Patients lost to follow-up (migrated, went abroad and downtime) were ruled out. All the patients included in this study received postoperative follow-up.

Statistical analysis. SPSS 19.0 (Chicago, IL, USA) statistical analysis software was used to collect, process, and analyze data. Continuous variables are presented as mean \pm SD (standard deviation). Continuous variables with skewed distribution are presented as median and interquartile range. Classified variables are presented as the absolute percentage. The Student's t-test was used for continuous variables, and the $\chi^{2}$ test was used for the comparison of classified variables. $\mathrm{P}<0.05$ suggested that the difference was statistically significant. Pearson's correlation analysis was used for the statistics of the correlation between various risk factor indexes, and the correlation coefficient $r$ was calculated.

\section{Results}

Nasopharyngeal CT index evaluation for pediatric patients with OSAHS before and after adenoidectomy (mean $\pm S D$ ). Nasopharyngeal X-ray was used to review patients after transoral endoscopic adenoidectomy to determine the results of surgery. The results showed that the postoperative $\mathrm{A} / \mathrm{N}$ ratio $(0.23 \pm 0.15)$ in 98 patients was significantly decreased $(\mathrm{T}=21.27$, $\mathrm{P}=0.03)$. The $\mathrm{D}$-value $(4.4 \pm 1.6 \mathrm{~mm})$ was significantly decreased $(\mathrm{T}=18.92, \mathrm{P}=0.03)$. The anatomically obstructive factor was removed, indicating that the surgery was successful (Table II).

Statistics and analysis of clinical blood test results for pediatric patients with OSAHS (mean $\pm S D$ ). $\mathrm{CD}^{+} \mathrm{T}$-cell count and percentage, $\mathrm{CD} 4{ }^{+} \mathrm{T}$-cell count and percentage, and $\mathrm{CD} 8^{+} \mathrm{T}$-cell count and percentage in pediatric patients were collected and recorded, followed by statistical analysis. We found that the postoperative $\mathrm{CD} 4^{+} \mathrm{T}$-cell count and percentage in patients were increased significantly $(\mathrm{P}=0.01)$, and the $\mathrm{CD} 4^{+} / \mathrm{CD}^{+}{ }^{+}$ratio was increased significantly $(\mathrm{P}=0.01)$. The changes of $\mathrm{CD}^{+} \mathrm{T}$ lymphocyte count and $\mathrm{CD} 8^{+} \mathrm{T}$ cells were not significantly different $(\mathrm{P}>0.05)$ (Table III).

Evaluation of sleep quality of pediatric patients with OSAHS before and after adenoidectomy (mean $\pm S D$ ). Through postoperative follow-up observation and the comparison of the number of awakenings and average continuous sleep time during the sleep of patients with OSAHS before and after adenoidectomy, the number of awakenings during sleep after surgery was found to be decreased significantly $(\mathrm{T}=19.33, \mathrm{P}=0.03)$; the average continuous sleep time was $612.43 \pm 12.63 \mathrm{~min}$, which 
Table III. Classified statistical results of T lymphocyte subsets at each follow-up for pediatric patients with OSAHS before and after transoral endoscopic adenoidectomy.

\begin{tabular}{|c|c|c|c|c|c|c|}
\hline Item & Before surgery & $\begin{array}{c}3 \text { weeks } \\
\text { after surgery }\end{array}$ & $\begin{array}{c}6 \text { weeks } \\
\text { after surgery }\end{array}$ & $\begin{array}{c}12 \text { weeks } \\
\text { after surgery }\end{array}$ & F-value & P-value \\
\hline $\mathrm{CD}^{+} \mathrm{T}$ cell count $(/ \mathrm{l})$ & $1237.4 \pm 128.48$ & $957.43 \pm 74.29$ & $967.68 \pm 58.52$ & $913.38 \pm 124.62$ & 0.38 & 0.66 \\
\hline $\mathrm{CD}^{+} \mathrm{T}$ cell percentage $(\%)$ & $0.58 \pm 0.24$ & $0.52 \pm 0.17$ & $0.68 \pm 0.12$ & $0.62 \pm 0.28$ & 0.43 & 0.66 \\
\hline $\mathrm{CD}^{+} \mathrm{T}$ cell count $(/ \mathrm{l})$ & $461.74 \pm 85.58$ & $504.63 \pm 69.53$ & $709.43 \pm 92.53$ & $712.29 \pm 78.55$ & 0.52 & 0.59 \\
\hline $\mathrm{CD}^{+}{ }^{+} \mathrm{T}$ cell percentage $(\%)$ & $39.21 \pm 12.37$ & $52.68 \pm 18.74$ & $59.95 \pm 12.39$ & $63.33 \pm 9.43$ & 6.39 & 0.01 \\
\hline $\mathrm{CD}^{+} \mathrm{T}$ cell count $(/ \mathrm{l})$ & $327.32 \pm 54.55$ & $495.79 \pm 75.82$ & $593.24 \pm 55.46$ & $601.93 \pm 35.52$ & 0.84 & 0.51 \\
\hline $\mathrm{CD}^{+} \mathrm{T}$ cell percentage $(\%)$ & $439.43 \pm 72.44$ & $501.74 \pm 101.76$ & $479.42 \pm 117.41$ & $463.74 \pm 92.41$ & 0.32 & 0.74 \\
\hline $\mathrm{CD} 4^{+} / \mathrm{CD}^{+}$ & $0.98 \pm 1.45$ & $1.48 \pm 0.19$ & $1.88 \pm 1.16$ & $2.24 \pm 0.36$ & 2.56 & 0.01 \\
\hline
\end{tabular}

OSAHS, obstructive sleep apnea-hypopnea syndrome.

Table IV. Sleep quality index evaluation at follow-up for pediatric patients with OSAHS (mean \pm SD).

\begin{tabular}{lccrrr}
\hline Index & Case no. (n) & Before surgery & After surgery & T-value & P-value \\
\hline No. of awakenings during sleep & 98 & $18.74 \pm 7.92$ & $2.32 \pm 1.51$ & 19.27 \\
Continuous sleep time (min) & 98 & $384.33 \pm 24.73$ & $612.43 \pm 12.36$ & 18.93 & 0.03 \\
Average $\mathrm{SPO}_{2}$ during sleep (\%) & 98 & $86.44 \pm 7.21$ & $95.33 \pm 2.79$ & 21.28 \\
AHI during sleep & 98 & $48.31 \pm 12.78$ & $9.61 \pm 10.54$ & 32.73 \\
\hline
\end{tabular}

OSAHS, obstructive sleep apnea-hypopnea syndrome; AHI, apnea-hypopnea index.

Table V. Evaluation of mean arterial pressure and blood biochemical indexes in pediatric patients with OSAHS before and after adenoidectomy (mean $\pm \mathrm{SD})$.

\begin{tabular}{|c|c|c|c|c|c|}
\hline Item & BMI $\left(\mathrm{kg} / \mathrm{m}^{2}\right)$ & MAP (mmHg) & FBG (mmol/l) & LDL-C (mmol/l) & $\mathrm{TG}(\mathrm{mmol} / \mathrm{l})$ \\
\hline Before operation & $21.4 \pm 3.4$ & $107.2 \pm 13.1$ & $5.37 \pm 1.62$ & $3.09 \pm 1.48$ & $1.58 \pm 0.24$ \\
\hline 3 weeks after surgery & $21.1 \pm 1.2$ & $75.0 \pm 14.2$ & $5.68 \pm 0.12$ & $3.11 \pm 0.24$ & $1.62 \pm 0.28$ \\
\hline 6 weeks after surgery & $18.7 \pm 0.5$ & $72.6 \pm 19.5$ & $4.73 \pm 0.25$ & $2.01 \pm 0.17$ & $1.02 \pm 0.85$ \\
\hline 12 weeks after surgery & $17.2 \pm 2.3$ & $73.6 \pm 12.7$ & $4.89 \pm 1.03$ & $1.92 \pm 0.33$ & $0.93 \pm 0.94$ \\
\hline F-value & 2.37 & 2.97 & 0.26 & 2.37 & 3.35 \\
\hline P-value & 0.013 & 0.026 & 0.462 & 0.004 & 0.035 \\
\hline
\end{tabular}

OSAHS, obstructive sleep apnea-hypopnea syndrome; BMI, body mass index; MAP, mean arterial pressure; LDL-C, low-density lipoprotein cholesterol; TG, triglyceride.

was significantly increased compared with before surgery $(\mathrm{T}=18.93, \mathrm{P}=0.03)$; the average oxyhemoglobin saturation during sleep was $95.3 \pm 2.7 \%$, which was significantly higher than that before surgery $(\mathrm{T}=21.28, \mathrm{P}=0.03)$ (Table IV).

Evaluation of MAP and blood biochemical indexes in pediatric patients with OSAHS before and after adenoidectomy (mean $\pm S D$ ). Through the measurement of mean arterial pressure (MAP), BMI, and various blood biochemical indexes in pediatric patients before and after transoral endoscopic adenoidectomy, it was found that MAP was $75.0 \pm 14.2 \mathrm{mmHg}$ in the third week after surgery, which was significantly decreased compared with that before surgery $(F=2.97, P=0.026)$. From the sixth week after surgery, low-density lipoprotein cholesterol (LDL-C) was $2.01 \pm 0.16 \mathrm{mmol} / \mathrm{l}$, which was significantly decreased compared with that before surgery. Triglyceride (TG) level was $1.02 \pm 0.88 \mathrm{mmol} / 1$ in the sixth week after surgery, which was significantly decreased compared with that before surgery $(\mathrm{F}=3.35, \mathrm{P}=0.035)$. However, there was no significant difference in fasting blood glucose $(\mathrm{F}=0.26$, $\mathrm{P}=0.462$ ) (Table V).

Correlation analysis of $C D 4^{+} / C D 8^{+} T$ lymphocyte ratio and $M A P$. It was found through previous studies that effective adenoidectomy significantly improved the peripheral blood $\mathrm{CD}^{+} / \mathrm{CD}^{+} \mathrm{T}$-cell ratio in pediatric patients with OSAHS. 
Table VI. Correlation analysis of $\mathrm{CD}^{+} / \mathrm{CD}^{+}$ratio and various clinical test indexes.

\begin{tabular}{|c|c|c|c|c|c|c|c|c|}
\hline Index & Gender & Age & $\begin{array}{l}\text { Course of OSAHS } \\
\text { (months) }\end{array}$ & $\begin{array}{c}\text { Fasting blood } \\
\text { glucose }(\mathrm{mmol} / \mathrm{l})\end{array}$ & $\begin{array}{c}\text { MAP } \\
(\mathrm{mmHg})\end{array}$ & $\begin{array}{c}\mathrm{TG} \\
(\mathrm{mmol} / \mathrm{l})\end{array}$ & $\begin{array}{l}\text { LDL-C } \\
(\mathrm{mmol} / \mathrm{l})\end{array}$ & $\begin{array}{c}\text { BMI } \\
\left(\mathrm{kg} / \mathrm{m}^{2}\right)\end{array}$ \\
\hline \multicolumn{9}{|c|}{$\mathrm{CD}^{+} / \mathrm{CD}^{+}$} \\
\hline $\mathrm{r}$ & 0.02 & 0.35 & 0.17 & 0.08 & -1.33 & 0.23 & 0.16 & 0.14 \\
\hline $\mathrm{P}$-value & 0.331 & 0.722 & 0.040 & 0.181 & 0.001 & 0.299 & 0.022 & 0.017 \\
\hline Index & $\mathrm{A} / \mathrm{N}$ & AHI & $\begin{array}{l}\text { Continuous sleep } \\
\text { time (min) }\end{array}$ & $\begin{array}{l}\text { No. of awakening } \\
\text { during sleep }\end{array}$ & $\begin{array}{c}\mathrm{AHI} \\
\text { grading }\end{array}$ & $\begin{array}{c}\text { Average } \\
\text { oxyhemoglobin } \\
\text { saturation } \\
\text { during sleep }\end{array}$ & & \\
\hline \multicolumn{9}{|c|}{$\mathrm{CD}^{+} / \mathrm{CD}^{+}$} \\
\hline $\mathrm{r}$ & 0.17 & 0.45 & 0.16 & 0.49 & 0.98 & 1.04 & & \\
\hline P-value & 0.272 & 0.493 & 0.731 & 0.606 & 0.371 & 0.010 & & \\
\hline
\end{tabular}

OSAHS, obstructive sleep apnea-hypopnea syndrome; MAP, mean arterial pressure; TG, triglyceride; LDL-C, low-density lipoprotein cholesterol; BMI, body mass index.

Table VII. Linear-regression analysis of influential factor of $\mathrm{CD}^{+} / \mathrm{CD} 8^{+} \mathrm{T}$ lymphocyte ratio in pediatric patients with $\mathrm{OSAHS}$.

\begin{tabular}{|c|c|c|c|c|c|c|c|}
\hline \multirow[b]{2}{*}{ Variables } & \multirow[b]{2}{*}{$\beta$} & \multirow[b]{2}{*}{$\mathrm{SE}$} & \multirow[b]{2}{*}{$\beta^{\prime}$} & \multirow[b]{2}{*}{$\mathrm{t}$} & \multirow[b]{2}{*}{$\mathrm{P}$-value } & \multicolumn{2}{|c|}{$95 \% \mathrm{CI}$} \\
\hline & & & & & & Upper limit & Lower limit \\
\hline Course of OSAHS & 0.531 & 0.14 & 0.764 & 1.412 & 0.39 & 0.26 & 0.81 \\
\hline LDL-C & 0.768 & 0.08 & 0.673 & 1.673 & 0.34 & 0.88 & 0.61 \\
\hline $\begin{array}{l}\text { Average oxyhemoglobin } \\
\text { saturation during sleep }\end{array}$ & 0.581 & 0.10 & 0.642 & 18.652 & 0.03 & 0.78 & 0.39 \\
\hline MAP & 0.435 & 0.04 & 0.782 & 8.37 & 0.03 & 0.51 & 0.36 \\
\hline BMI & 0.768 & 0.08 & 0.871 & 0.981 & 0.50 & 0.61 & 0.92 \\
\hline
\end{tabular}

OSAHS, obstructive sleep apnea-hypopnea syndrome; LDL-C, low-density lipoprotein cholesterol; MAP, mean arterial pressure; BMI, body mass index.

However, we found that the potential influential factors including the $24 \mathrm{~h}$ MAP, $24 \mathrm{~h}$ sleep time, $24 \mathrm{~h}$ average oxyhemoglobin saturation, BMI, blood TG, blood LDL-C, and course of OSAHS, may be related to the $\mathrm{CD} 4^{+} / \mathrm{CD} 8^{+} \mathrm{T}$-cell ratio via review of the literature and clinical experience. The $\mathrm{CD}^{+} / \mathrm{CD}^{+}$T-cell ratio was taken as the independent variable to perform the correlation analysis with a series of indexes mentioned above. Pearson's correlation analysis showed that the $\mathrm{CD}^{+} / \mathrm{CD}^{+} \mathrm{T}$ lymphocyte ratio had a significantly negative correlation with $24 \mathrm{~h}$ MAP ( $\mathrm{r}=-1.33, \mathrm{P}=0.001)$, a positive correlation with average oxyhemoglobin saturation during sleep $(r=1.04, P=0.010)$, and no significant correlation with 24-h sleep time or $24 \mathrm{~h}$ average oxyhemoglobin saturation $(\mathrm{P}>0.05)$ (Tables VI and VII).

\section{Discussion}

With recent development of internal passing technology, transoral endoscopic adenoidectomy has gradually replaced adenoidectomy and has become the primary surgical method for the treatment of adenoidal hypertrophy and apnea syndrome caused by adenoidal hypertrophy in children. Its main advantages are that it is minimally invasive and the postoperative recovery is fast. The nasopharyngeal space of children is limited, but blood flow is widely distributed to that region. Therefore, blind excision usually causes bleeding and incomplete resection of the adenoid may cause it to develop again (13). In terms of surgical evaluation, the $\mathrm{A} / \mathrm{N}$ ratio and D-value are widely used to analyze the nasopharyngeal anatomical structure in OSAHS. In our study, 98 pediatric patients diagnosed with adenoidal hypertrophy were randomly enrolled after being screened according to the inclusion and exclusion criteria, and underwent transoral endoscopic adenoidectomy. After surgery, the $\mathrm{A} / \mathrm{N}$ ratio was $0.23 \pm 0.15$, which was significantly decreased $(\mathrm{T}=21.27, \mathrm{P}=0.03)$ and the D-value was $4.4 \pm 1.6 \mathrm{~mm}$, which was significantly decreased ( $\mathrm{T}=18.93, \mathrm{P}=0.03$ ). This shows that the potential anatomical obstructive factors in the nasopharynx of children with OSAHS were removed after adenoidectomy, which is important for the treatment of OSAHS. 
In the past, some scholars hypothesized that the largest effect of OSAHS on pediatric patients is a series of stress reactions caused by hypoxia. The currently recognized obstructive sleep apnea (OSA) can promote and activate the systemic inflammatory response, including a variety of pro-inflammatory cytokines, such as interleukin (IL)-6, IFN- $\gamma$, and TNF- $\alpha$ (14-16).

It was found that the anti-inflammatory cytokine, IL-10, is significantly decreased in children with OSA, which indicates that there are potential inflammatory responses in the body of patients with OSA, and that these inflammatory cytokines have certain effects on regulating blood lipids, blood glucose, and blood pressure (17). The signaling cascades initiated by hypoxia are controlled by genes. At present, the promoter region of the Foxp3 gene has been shown to play an important role in regulatory $\mathrm{T}$ (Treg) cell transcription and differentiation, and is highly dependent on methylation in children with OSA. Treg cells are capable of differentiating into $\mathrm{CD} 4^{+}$ $\mathrm{T}_{\mathrm{h}}$ cells, which play an important role in certain autoimmune diseases (18).

After removing the obstructive factors, we evaluated the peripheral blood $\mathrm{T}$ lymphocyte subsets and a variety of blood biochemical indexes in pediatric patients, and found that the $\mathrm{CD}^{+} \mathrm{T}$ cell count and percentage were increased significantly after surgery $(\mathrm{P}=0.01)$. Additionally, the $\mathrm{CD} 4^{+} / \mathrm{CD}^{+}$ratio was increased significantly $(\mathrm{P}=0.01)$. Our results were consistent with those of previous studies $(16,18)$.

It is reported in the literature that there is a certain correlation between OSAHS and obesity. The relationship between obesity and OSA was initially identified in epidemiological studies (19). In many developed countries, there appears to be a relationship between obesity and OSA in children. With increasing numbers of children being diagnosed with OSA, more non-obese children with OSA have been accompanied with adenoidal hypertrophy. However, a study on OSA in obese and non-obese children showed that the Mallampati score of obese children was significantly higher, greatly increasing their risk of OSA (20). However, such risk is not caused by lymph node hyperplasia. Instead, it is because substantial space is occupied and breathing is therefore directly inhibited. The oxidative stress caused by hypoxia leads to disorder in the metabolism of blood sugar, blood fat and protein. Therefore, blood sugar and blood fat are increased, and large amounts of lactose produced by anaerobic glycolysis make it easier for pediatric patients to suffer from metabolic acidosis (20). Combined with the inhibition in transcription and differentiation of Treg cells, this leads to a significant decrease of $\mathrm{CD}^{+}{ }^{+} \mathrm{T}_{\mathrm{h}}$ cells in the body. As a result, the patient's resistance to outside pathogens is weakened $\left(\mathrm{CD}^{+}{ }^{+} \mathrm{T}_{\mathrm{h}}\right.$ cells are mainly involved in specific cellular immunity), and some autoimmune diseases may occur, such as type 1 diabetes (21).

In addition, it is common in children with OSAHS that long-term sleep disorder causes sympathetic nerve dysfunction, reflex blood pressure increase, and other internal changes (22). In our study, the blood lipid levels of most patients were close to the normal upper limit, and even exceeded it. In addition, a potential decline in glucose tolerance occurred in some patients. However, MAP was $75.0 \pm 14.2 \mathrm{mmHg}$ in the third week after adenoidectomy, which was significantly decreased compared with that before surgery $(\mathrm{F}=2.97, \mathrm{P}=0.026)$. From the sixth week after surgery, LDL-C was $2.01 \pm 0.17 \mathrm{mmol} / 1$, which was significantly decreased compared with that before surgery. TG level was $1.02 \pm 0.85 \mathrm{mmol} / \mathrm{l}$ in the sixth week, which was significantly decreased compared with that before surgery $(\mathrm{F}=3.35, \mathrm{P}=0.035)$. We believe that the factor causing anatomical obstruction in pediatric patients was fundamentally removed. Therefore, the anoxic condition of children was improved and the metabolic activity in the body gradually returned to normal.

We found significant changes in a variety of indexes before and after surgery. Furthermore, we hope to conduct correlation analyses to study the internal relation behind these indexes. We conducted the Pearson's correlation analysis with $\mathrm{CD}^{+} / \mathrm{CD}^{+} \mathrm{T}$ lymphocyte ratio as the independent variable and other indexes as dependent variables, and found that the $\mathrm{CD}^{+} / \mathrm{CD}^{+} \mathrm{T}$ lymphocyte ratio had a negative correlation with MAP ( $\mathrm{r}=-1.33, \mathrm{P}=0.001)$, and a positive correlation with average oxyhemoglobin saturation during sleep $(\mathrm{r}=1.04$, $\mathrm{P}=0.010)$.

Present studies suggest that there is no significant direct correlation between blood pressure and T-cell subset differentiation (23). We suspect through the above analysis and literature review that this may be because the change of oxyhemoglobin saturation in pediatric patients changes the $\mathrm{CD} 4^{+} / \mathrm{CD}^{+} \mathrm{T}$ lymphocyte ratio. Additionally, the oxidative stress caused by hypoxia and increases of $\mathrm{H}^{+}$and $\mathrm{CO}_{2}$ concentration increase the tension of sympathetic nerves through the effect of the carotid sinus and aortic arch chemoreceptor, thus increasing blood pressure (23). Therefore, we believe that MAP and peripheral blood $\mathrm{T}$ lymphocyte subsets can be used as important indexes for evaluating disease progression in children with OSAHS. This further supports the idea that regardless of treatment method, the key to treatment of OSAHS is to eliminate the primary cause of obstruction in patients, to correct the anoxic condition.

In conclusion, we believe transoral endoscopic adenoidectomy has a very good therapeutic effect on removing upper respiratory tract obstruction in pediatric patients with OSAHS. Hypoxia and MAP are the primary factors influencing the peripheral blood $\mathrm{CD}^{+} / \mathrm{CD}^{+} \mathrm{T}$ lymphocyte ratio, and can be used as indexes for evaluating disease progression in children with OSAHS.

\section{References}

1. Coman AC, Borzan C, Vesa CS and Todea DA: Obstructive sleep apnea syndrome and the quality of life. Clujul Med 89: 390-395, 2016

2. Lam JC, Mak JC and Ip MS: Obesity, obstructive sleep apnoea and metabolic syndrome. Respirology 17: 223-236, 2012.

3. Dempsey JA, Veasey SC, Morgan BJ and O'Donnell CP: Pathophysiology of sleep apnea. Physiol Rev 90: 47-112, 2010.

4. Wang Q, Ou Q, Tian XT, Chen YC, Nie ZQ and Gao XL: Analysis of long-term compliance to continuous positive airway pressure in patients with obstructive sleep apnea. Zhonghua Yi Xue Za Zhi 96: 2380-2384, 2016 (In Chinese).

5. Feng HW, Jiang T, Zhang HP, Wang Z, Zhang HL, Zhang H, Chen XM, Fan XL, Tian YD and Jia T: Comparisons of thyroid hormone, intelligence, attention, and quality of life in children with obstructive sleep apnea hypopnea syndrome before and after endoscopic adenoidectomy. BioMed Res Int 2015: 523716, 2015.

6. Sforza E, Saint Martin M, Thomas T, Collet P, Garet M, Barthélémy JC and Roche F: Risk factors of osteoporosis in healthy elderly with unrecognized obstructive sleep apnea: role of physical activity. Sleep Med 22: 25-32, 2016. 
7. Tauman R, Lavie L, Greenfeld M and Sivan Y: Oxidative stress in children with obstructive sleep apnea syndrome. J Clin Sleep Med 10: 677-681, 2014.

8. Kim J, Gozal D, Bhattacharjee R and Kheirandish-Gozal L: TREM-1 and pentraxin-3 plasma levels and their association with obstructive sleep apnea, obesity, and endothelial function in children. Sleep 36: 923-931, 2013.

9. Jiang N, Zhou A, Prasad B, Zhou L, Doumit J, Shi G, Imran H, Kaseer B, Millman R and Dudley SC Jr: Obstructive sleep apnea and circulating potassium channel levels. J Am Heart Assoc 5: e003666, 2016.

10. Chapman JL, Serinel Y, Marshall NS and Grunstein RR: Residual daytime sleepiness in obstructive sleep apnea after continuous positive airway pressure optimization: causes and management. Sleep Med Clin 11: 353-363, 2016.

11. Roubille F, Fischer K, Guensch DP, Tardif JC and Friedrich MG: Impact of hyperventilation and apnea on myocardial oxygenation in patients with obstructive sleep apnea - An oxygenation-sensitive CMR study. J Cardiol 69: 489-494, 2017.

12. Marcus CL, Brooks LJ, Draper KA, Gozal D, Halbower AC, Jones J, Schechter MS, Sheldon SH, Spruyt K, Ward SD, et al; American Academy of Pediatrics: Diagnosis and management of childhood obstructive sleep apnea syndrome. Pediatrics 130 576-584, 2012

13. El-Badrawy A and Abdel-Aziz M: Transoral endoscopic adenoidectomy. Int J Otolaryngol 2009: 949315, 2009.

14. Tauman R, O'Brien LM and Gozal D: Hypoxemia and obesity modulate plasma C-reactive protein and interleukin-6 levels in sleep-disordered breathing. Sleep Breath 11: 77-84, 2007.

15. Gozal D, Serpero LD, Kheirandish-Gozal L, Capdevila OS, Khalyfa A and Tauman R: Sleep measures and morning plasma TNF-alpha levels in children with sleep-disordered breathing. Sleep 33: 319-325, 2010.
16. Tam CS, Wong M, McBain R, Bailey S and Waters KA: Inflammatory measures in children with obstructive sleep apnoea. J Paediatr Child Health 42: 277-282, 2006.

17. GozalD, Serpero LD, Sans Capdevila O and Kheirandish-GozalL: Systemic inflammation in non-obese children with obstructive sleep apnea. Sleep Med 9: 254-259, 2008.

18. Basoglu OK and Tasbakan MS: Comparison of clinicalcharacteristics in patients with obesity hypoventilation syndrome and obese obstructive sleep apnea syndrome: a case-control study. Clin Respir J 8: 167-174, 2014.

19. Pillai A, Warren G, Gunathilake W and Idris I: Effects of sleep apnea severity on glycemic control in patients with type 2 diabetes prior to continuous positive airway pressure treatment. Diabetes Technol Ther 13: 945-949, 2011.

20. Dayyat E, Kheirandish-Gozal L, Sans Capdevila O, Maarafeya MM and Gozal D: Obstructive sleep apnea in children: relative contributions of body mass index and adenotonsillar hypertrophy. Chest 136: 137-144, 2009.

21. Serr I, Fürst RW, Achenbach P, Scherm MG, Gökmen F, Haupt F, Sedlmeier EM, Knopff A, Shultz L, Willis RA, et al: Type 1 diabetes vaccine candidates promote human Foxp3(+)Treg induction in humanized mice. Nat Commun 7: 10991, 2016.

22. Arens R, Sin S, Nandalike K, Rieder J, Khan UI, Freeman K, Wylie-Rosett J, Lipton ML, Wootton DM, McDonough JM, et al: Upper airway structure and body fat composition in obese children with obstructive sleep apnea syndrome. Am J Respir Crit Care Med 183: 782-787, 2011.

23. Bhattacharjee R, Kim J, Alotaibi WH, Kheirandish-Gozal L, Capdevila OS and Gozal D: Endothelial dysfunction in children without hypertension: potential contributions of obesity and obstructive sleep apnea. Chest 141: 682-691, 2012. 